\title{
SiMYB19 from Foxtail Millet (Setaria italica) Confers Transgenic Rice Tolerance to High Salt Stress in the Field
}

\author{
Chengjie Xu ${ }^{1,2,+}$, Mingzhao Luo ${ }^{2,+}$, Xianjun Sun ${ }^{2}$, Jiji Yan ${ }^{3}$, Huawei Shi ${ }^{1}$, Huishu Yan ${ }^{1}$, Rongyue Yan ${ }^{1}$, \\ Shuguang Wang ${ }^{1}$, Wensi Tang ${ }^{2}$, Yongbin Zhou ${ }^{2}$, Chunxiao Wang ${ }^{2}$, Zhaoshi Xu ${ }^{2}{ }^{\oplus}$, Jun Chen ${ }^{2}$, Youzhi Ma ${ }^{2}$, \\ Qiyan Jiang ${ }^{2}$, Ming Chen ${ }^{2, *}$ and Daizhen Sun ${ }^{1, *}$
}

\section{check for}

updates

Citation: Xu, C.; Luo, M.; Sun, X.;

Yan, J.; Shi, H.; Yan, H.; Yan, R.; Wang,

S.; Tang, W.; Zhou, Y.; et al. SiMYB19

from Foxtail Millet (Setaria italica)

Confers Transgenic Rice Tolerance to

High Salt Stress in the Field. Int. J.

Mol. Sci. 2022, 23, 756. https://

doi.org/10.3390/ijms23020756

Academic Editors: Sergey Shabala,

Om Parkash Dhankher and P.V.

Vara Prasad

Received: 9 December 2021

Accepted: 8 January 2022

Published: 11 January 2022

Publisher's Note: MDPI stays neutral with regard to jurisdictional claims in published maps and institutional affiliations.

Copyright: (C) 2022 by the authors. Licensee MDPI, Basel, Switzerland. This article is an open access article distributed under the terms and conditions of the Creative Commons Attribution (CC BY) license (https:// creativecommons.org/licenses/by/ $4.0 /)$.

1 Key Laboratory of Sustainable Dryland Agriculture, College of Agriculture, Shanxi Agricultural University, Jinzhong 030801, China; xu1253824860@163.com (C.X.); mrshihuawei@163.com (H.S.); yanhs111@163.com (H.Y.); 18503483681@163.com (R.Y.); wsg6162@126.com (S.W.)

2 Institute of Crop Sciences, National Key Facility for Crop Gene Resources and Genetic Improvement, Key Laboratory of Biology and Genetic Improvement of Triticeae Crops, Chinese Academy of Agricultural Sciences (CAAS), Beijing 100081, China; caasluomingzhao@163.com (M.L.); sunxianjun@caas.cn (X.S.); tang_wensi@yeah.net (W.T.); houyongbin@caas.cn (Y.Z.); wangchunxiao@caas.cn (C.W.); xuzhaoshi@caas.cn (Z.X.); chenjun01@caas.cn (J.C.); mayouzhi@caas.cn (Y.M.); jiangqiyan@caas.cn (Q.J.)

3 College of Life Sciences, Shanxi Normal University, Taiyuan 030006, China; jiiiyan19970316@163.com

* Correspondence: sdz64@126.com or sdz64@sxau.edu.cn (D.S.); chenming02@caas.cn (M.C.)

+ These authors contributed equally to this work.

\begin{abstract}
Salt stress is a major threat to crop quality and yield. Most experiments on salt stressrelated genes have been conducted at the laboratory or greenhouse scale. Consequently, there is a lack of research demonstrating the merit of exploring these genes in field crops. Here, we found that the R2R3-MYB transcription factor SiMYB19 from foxtail millet is expressed mainly in the roots and is induced by various abiotic stressors such as salt, drought, low nitrogen, and abscisic acid. SiMYB19 is tentatively localized to the nucleus and activates transcription. It enhances salt tolerance in transgenic rice at the germination and seedling stages. SiMYB19 overexpression increased shoot height, grain yield, and salt tolerance in field- and salt pond-grown transgenic rice. SiMYB19 overexpression promotes abscisic acid (ABA) accumulation in transgenic rice and upregulates the ABA synthesis gene OsNCED3 and the ABA signal transduction pathway-related genes OsPK1 and OsABF2. Thus, SiMYB19 improves salt tolerance in transgenic rice by regulating ABA synthesis and signal transduction. Using rice heterologous expression analysis, the present study introduced a novel candidate gene for improving salt tolerance and increasing yield in crops grown in saline-alkali soil.
\end{abstract}

Keywords: ABA pathway; foxtail millet; high salt stress; MYB transcription factor

\section{Introduction}

Salt stress adversely affects plant growth and development and has a serious impact on crop yield and quality. Eight hundred million hectares of soil worldwide are affected by salinity according to FAO data. Soil salinity affects over $20 \%$ of all arable land globally. This rate is expected to continue to increase [1]. Therefore, the selection of salt-tolerant crops is vital to the maintenance of grain production in saline-alkali soil, the expansion of cultivable land, and the assurance of food security. Foxtail millet (Setaria italica L.) belongs to the Gramineae family. It originated in China and has strong natural abiotic stress resistance [2], a small genome, and a short growth cycle. Therefore, it is an ideal model crop to study abiotic stress resistance in gramineous crops [2]. However, very little research has been conducted to date on the functional genome of foxtail millet. Furthermore, its stress-related regulatory network is poorly understood. Identification of the key stress resistance genes in foxtail millet and especially those with important practical field application may help facilitate the improvement of stress resistance in this plant and the other gramineous crops. 
MYB-like transcription factors perform various functions during plant growth and development. They regulate anthocyanidin biosynthesis and accumulation, lateral root and pollen development, and phytohormones [3]. Arabidopsis induces the expression of AtMYB2 and AtMYB15 by regulating ABA content under drought and high salt conditions $[4,5]$. $G A M Y B$ in rice is also an important regulator of gibberellin signal transduction [6]. The foregoing genes also play important roles in stress adaptation. The rice R2R3-MYB transcription factor (TF) OsMYB2 is strongly induced in response to salt and cold stress. OsMYB2 overexpression enhances tolerance to different abiotic stressors in OsMYB2 transgenic plants [7]. In Arabidopsis, certain R2R3-MYB TFs such as AtMYB2, AtMYB20, AtMYB44, AtMYB73, and $A t M Y B 74$ are induced by salt stress and regulate salt tolerance [8]. ZmMYB3R is a positive regulator of salt and drought resistance. Its ectopic expression significantly enhances transgenic plant tolerance to drought and salt stress [9]. The alfalfa TF MYB4 is activated by DNA methylation and/or histone modification in response to salt stress [10]. The poplar MYB TF PtrSSR1 enhances salt stress tolerance in transgenic plants [11]. Apple $M d M Y B 88$ and its homolog MdMYB124 regulate root xylem development and cell wall cellulose accumulation under drought conditions. Therefore, these genes regulate water transport under drought stress [12]. Several studies have reported on the roles of MYB TFs in abiotic stress response. However, it is difficult to regulate the strength of abiotic stressors such as salinity because of the long duration of field trials. Hence, most of the foregoing data were obtained from laboratory or greenhouse experiments. There is a lack of field trial data demonstrating the influences of MYB-like TFs on abiotic stress resistance in field crops. Functional evaluation of stress-related genes in field crops may help establish whether they merit further investigation and should be applied in practical breeding research.

In our previous work, we analyzed the transcriptome of foxtail millet subjected to drought and salt stress and found that several MYB TFs responded to these and other stressors [13]. SiMYB19 and SiMYB56 were differentially expressed in drought stress transcriptome sequencing and were upregulated in prior studies. In the present study, we found that the MYB TF SiMYB19 was induced by salt stress. We transformed it into wild type (WT) Kitaake (Ki) rice and obtained stable T3 generation transgenic rice by Agrobacterium transformation. We transplanted the transgenic rice lines with the highest salt tolerance from the laboratory to the field and exposed them to various salt concentrations. SiMYB19 overexpression significantly improved survival in transgenic rice exposed to high salt concentrations $(0.5 \%(w / v) \mathrm{NaCl})$ and augmented grain yield in transgenic rice subjected to moderate salt concentrations $(0.3 \%(w / v) \mathrm{NaCl})$. Hence, SiMYB19 could be exploited to improve crop salt tolerance. We also identified the downstream network of SiMYB19 via qRT-PCR and analyzed the phenotypes of the transgenic rice plants.

\section{Results}

\subsection{SiMYB19 Gene Structure and Phylogenetic Tree Analysis}

In previous research, we performed RNA-seq on a stress-tolerant foxtail millet subjected to drought or salt $[13,14]$ and discovered that the MYB-like TF SiMYB19 (Seita.1G250600.1) significantly responded to salt stress. SiMYB19 was localized to the first chromosome of the foxtail millet genome. The genome sequence length was $1562 \mathrm{bp}$ and included three exons, two introns, and an 888 bp long open reading frame (ORF). SiMYB19 encodes a protein that was 295 amino acids (aa) in length (Figure 1A). The predicted molecular weight (MW) of SiMYB19 was $31.72 \mathrm{kDa}$, and its isoelectric point was 5.83. SiMYB19 contains two SANT conserved domains and belongs to the R2R3 subgroup of the MYB TF family (Figure 1B,C). The phylogenetic tree showed that the SiMYB19 protein has the highest homology with maize ZmLAF1 and with Arabidopsis AtMYB19, AtMYB18, and AtMYB45 (Figure 1C) [15]. 


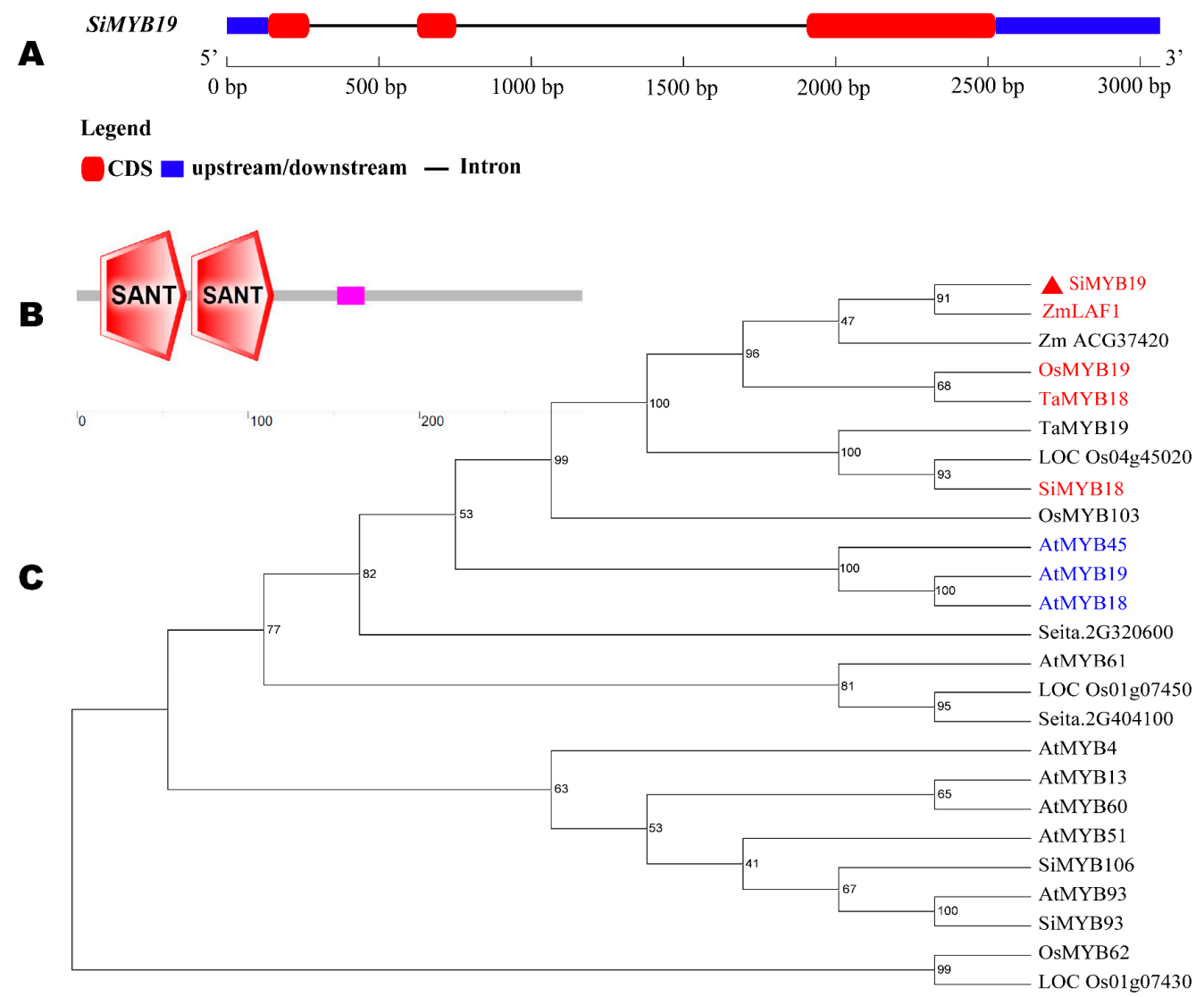

Figure 1. SiMYB19 gene and protein structure and phylogenetic tree. (A) SiMYB19 gene structure. Blue is untranslated region (UTR). Red is exon. Black is intron. (B) SiMYB19 protein structure. Red polygon is SANT conserved domain. Numbers represent length of aa sequence from $N$-terminal to C-terminal. (C) SiMYB19 phylogenetic tree. Solid red triangle is SiMYB19. Red indicates highest homology to genes in maize $(\mathrm{Zm})$, rice $(\mathrm{Os})$, wheat $(\mathrm{Ta})$, and foxtail millet (Si). Blue indicates highest homology to genes in Arabidopsis (At).

\subsection{SiMYB19 Expression Profile in Foxtail Millet under Different Treatments}

We analyzed the SiMYB19 expression profile after treating seedlings with $100 \mathrm{mM}$ $\mathrm{NaCl}, 10 \%(w / v)$ PEG6000, $100 \mu \mathrm{M} \mathrm{ABA}, 0.2 \mathrm{mM} \mathrm{NO}_{3}{ }^{-}$(LN (low nitrogen); nitrogen deficiency) and $100 \mu \mathrm{M}$ IAA. SiMYB19 was expressed mainly in the roots (Figure 2A). It was strongly induced by $\mathrm{NaCl}$, drought, $\mathrm{LN}$, and $\mathrm{ABA}$ exposures and weakly induced by IAA (Figure 2B-F). Under $100 \mathrm{mM} \mathrm{NaCl}$, SiMYB19 expression reached a maximum at $6 \mathrm{~h}$ and was sixfold higher than that at $0 \mathrm{~h}$ (Figure 2B). Under 10\% (w/v) PEG6000, SiMYB19 expression reached a maximum at $6 \mathrm{~h}$ and was twentyfold higher than that at $0 \mathrm{~h}$ (Figure 2C). Under LN, SiMYB19 expression reached a maximum at $24 \mathrm{~h}$ (Figure 2D). Under $100 \mu \mathrm{M}$ ABA, SiMYB19 expression reached a maximum at $12 \mathrm{~h}$ and was sevenfold higher than that at $0 \mathrm{~h}$ (Figure $2 \mathrm{~F}$ ). 
A

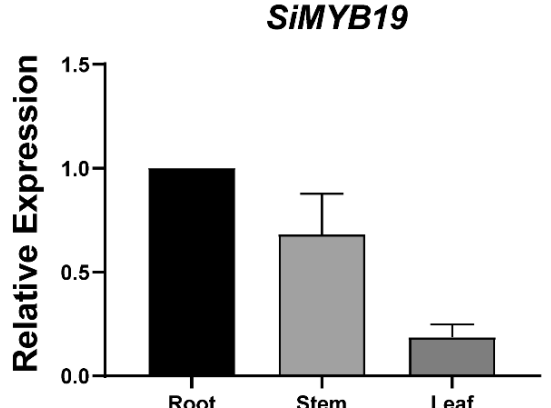

C

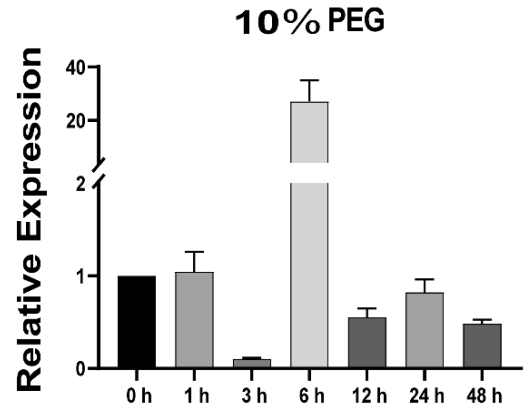

$\mathbf{E}$

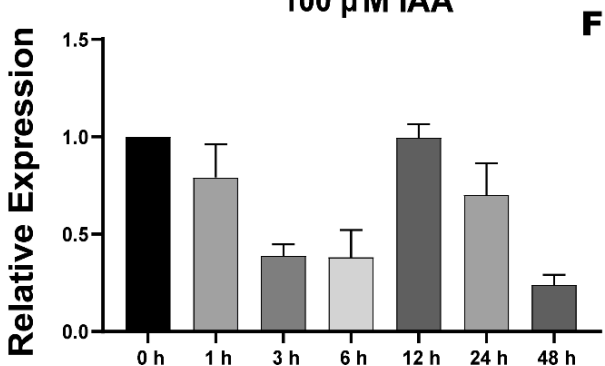

B

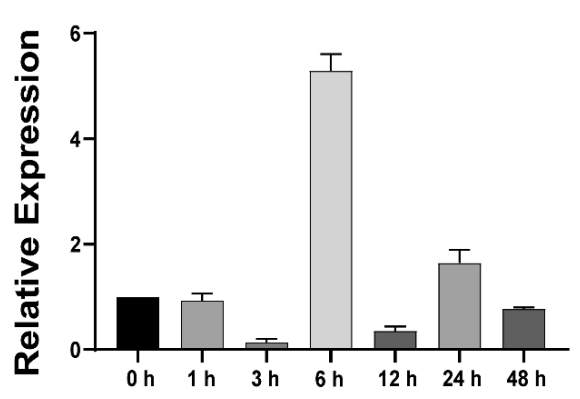

D

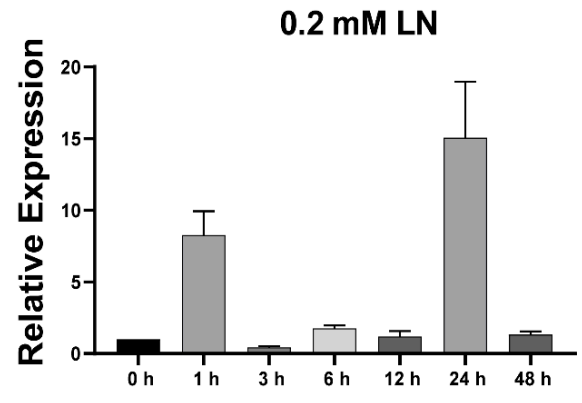

$100 \mu \mathrm{M} A B A$

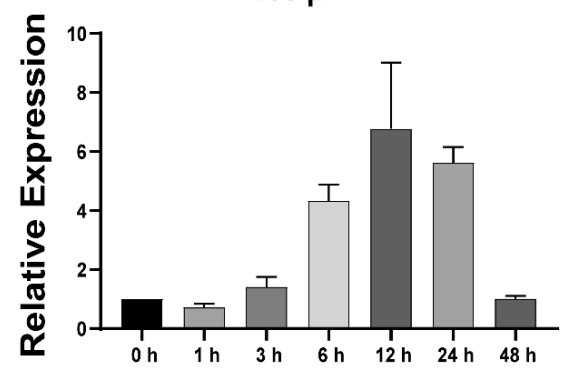

Figure 2. SiMYB19 expression profile in foxtail millet. (A) SiMYB19 expression in roots, stems, and leaves and in response to (B) $80 \mathrm{mM} \mathrm{NaCl},(\mathbf{C}) 10 \%(w / v)$ PEG6000, (D) low nitrogen (LN; $0.2 \mathrm{mM}$ $\mathrm{NO}_{3}{ }^{-}$), (E) $100 \mu \mathrm{M}$ auxin (IAA), and (F) $100 \mu \mathrm{M}$ abscisic acid (ABA). SiMYB19 expression was determined by qRT-PCR. Data are means $\pm \mathrm{SD}(n=3)$.

\subsection{SiMYB19 Tentatively Localizes to The Nucleus and Activates Transcription}

We generated a SiMYB19-GFP fusion vector controlled by the CaMV35S promoter to determine subcellular SiMYB19 protein localization. The vectors were transiently transformed in foxtail millet mesophyll protoplasts. The $16318 \mathrm{~h} G F P$ vector served as a positive control. The subcellular analysis indicated that the GFP-SiMYB19 protein tentatively localized to the nucleus (Figure 3A). We transformed the pBD-SiMYB19 vector and the negative control pGBKT7 empty vector into the AH109 yeast strain to identify transcription activation mediated by SiMYB19. The pBD-SiMYB19 transformants (BD-SiMYB19) grew on $\mathrm{SD} /-\operatorname{Trp} /$-His/-Ade selection medium and SD/-Trp/-His/-Ade plus X- $\alpha$-gal. By contrast, the negative control pGBKT7 empty vector (BD) did not grow on the selection medium (Figure 3B). Thus, SiMYB19 activated transcription in yeast. 
A
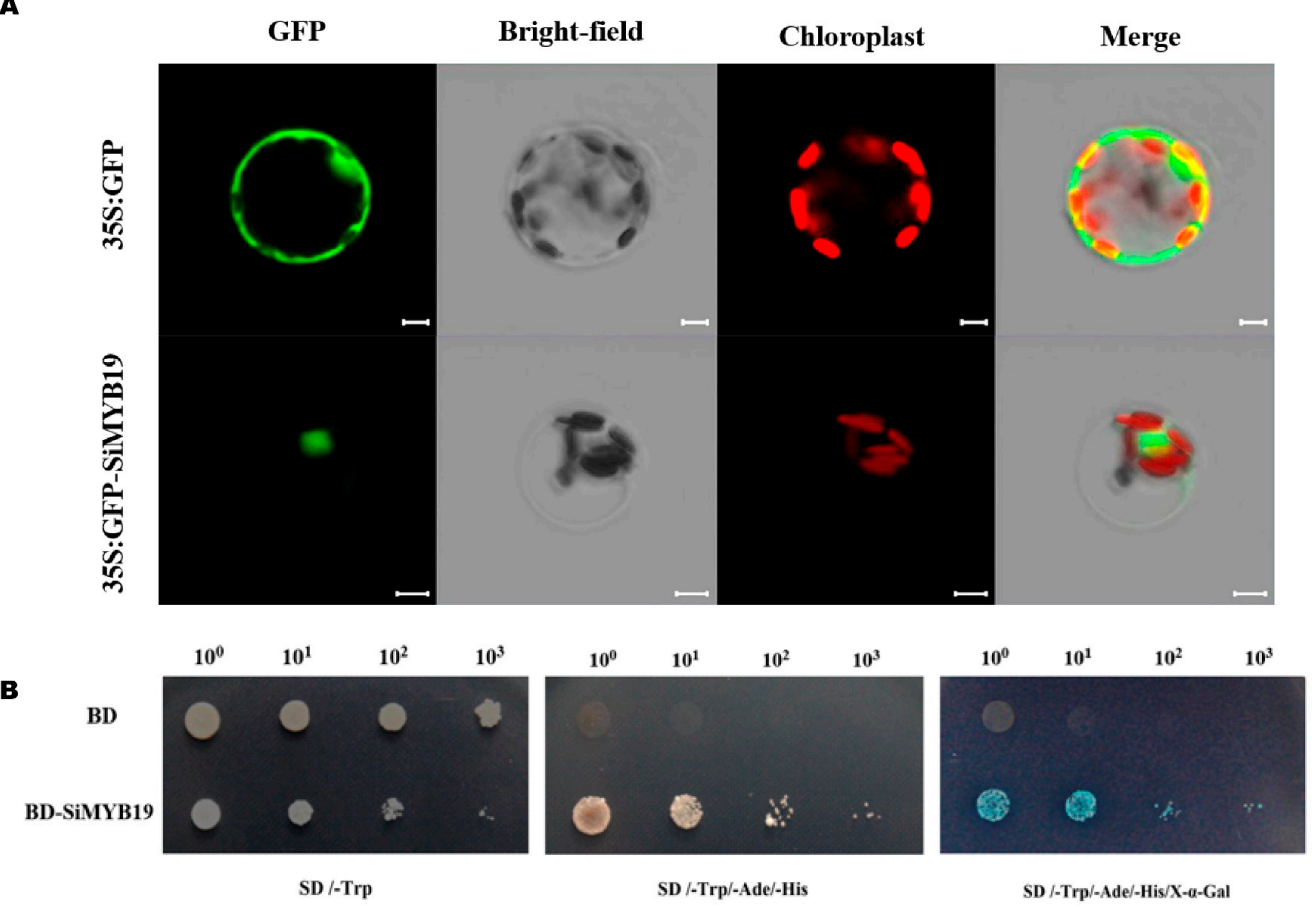

Figure 3. SiMYB19 subcellular localization and transcription activation assay. (A) Subcellular SiMYB19 localization in foxtail millet mesophyll protoplasts. The 35S:GFP-SiMYB19 and 35S:GFP control vectors were transiently expressed in foxtail millet mesophyll protoplasts. Fluorescence was observed under a Zeiss LSM980 confocal laser scanning microscope after $16 \mathrm{~h}$ transformation. Red is caused by chlorophyll fluorescence in chloroplasts. (B) SiMYB19 transcriptional activation assay. pGBKT7-SiMYB19 (BD-SiMYB19) was the expression vector, and the negative control pGBKT7 (BD) was the empty vector. Finally, dilution gradients are represented by $10^{0}, 10^{1}, 10^{2}$, and $10^{3}$.

\subsection{SiMYB19 Overexpression Enhanced Transgenic Rice Seedling Tolerance to Salt Stress}

Foxtail millet transformation is difficult to perform. To identify the functions of SiMYB19, we transformed it into rice. We identified T3 generation transgenic rice plants by PCR (Figure S1). The qRT-PCR disclosed that in response to $100 \mathrm{mM} \mathrm{NaCl}$, the transgenic rice lines OE-6, OE-8, and OE-9 had higher SiMYB19 expression levels than the WT (Figure S2). We analyzed greenhouse-raised, PCR-positive transgenic lines for salt tolerance. Under normal growth conditions, the phenotypes of the transgenic and WT rice lines did not significantly differ from each other (Figure 4A). After $100 \mathrm{mM} \mathrm{NaCl}$ treatment for $5 \mathrm{~d}$, there was significantly less leaf curling in OE-6, OE-8, and OE-9 than the WT (Figure 4B). The greenhouse salt tolerance analysis revealed that the transgenic line OE-6 had the highest survival rate (Figure 4C). Thus, it was selected for the subsequent salt tolerance analyses in the salt ponds and the field. After recovery to normal growth conditions, the transgenic line survival rates $(20-40 \%)$ were significantly $(p<0.05)$ higher than that of the WT $(5 \%)$ (Figure 4A-D). After salt treatment, the malondialdehyde (MDA) concentrations in the transgenic rice were significantly $(p<0.05)$ lower than that of the WT (Figure 4E). Plant height $(p<0.05)$, root length $(p<0.05)$, aboveground fresh weight $(p<0.05)$, underground fresh weight $(p<0.01)$, aboveground dry weight $(p<0.01)$, and underground dry weight $(p<0.01)$ were significantly higher for the transgenic rice plants than the WT (Figure 4F-K). Therefore, SiMYB19 overexpression significantly improved greenhouse-grown transgenic rice plant salt stress tolerance. 


\section{A}

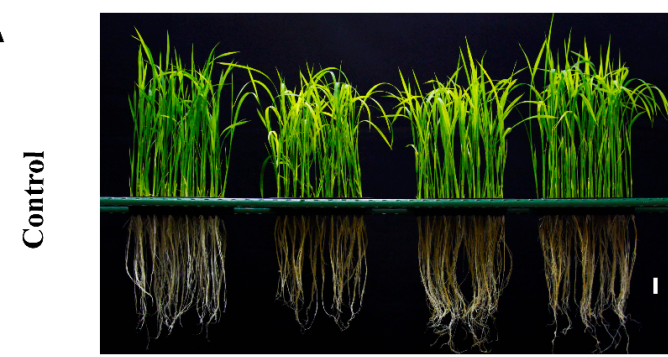

B

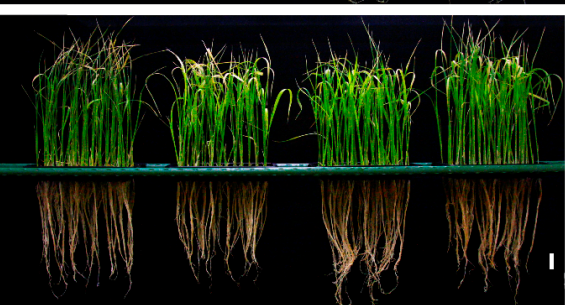

C

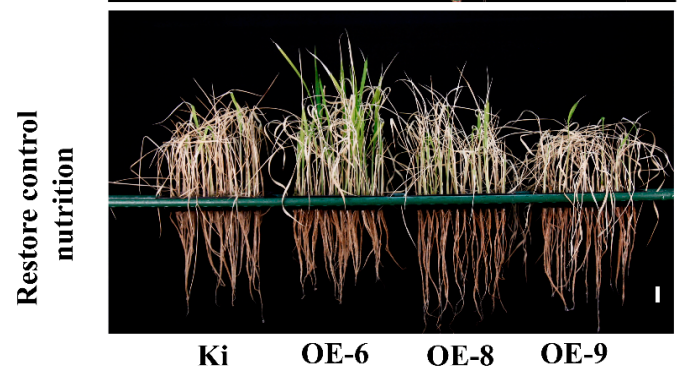

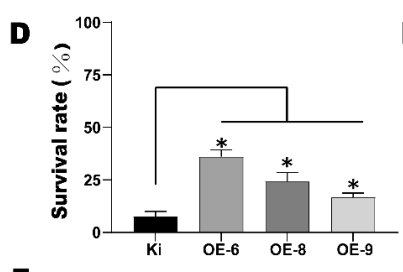

$\mathbf{F}$
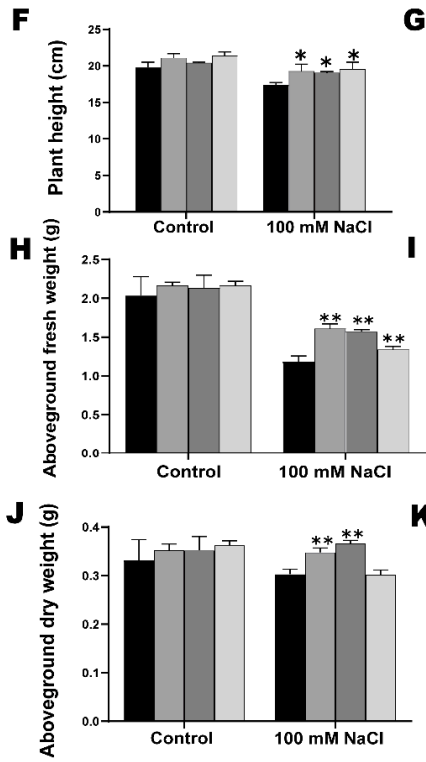
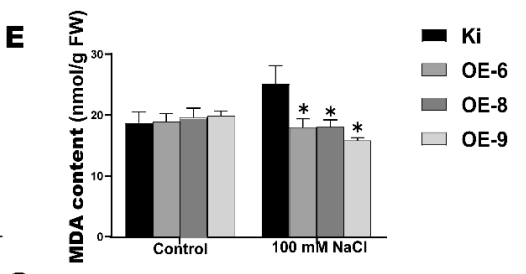

G
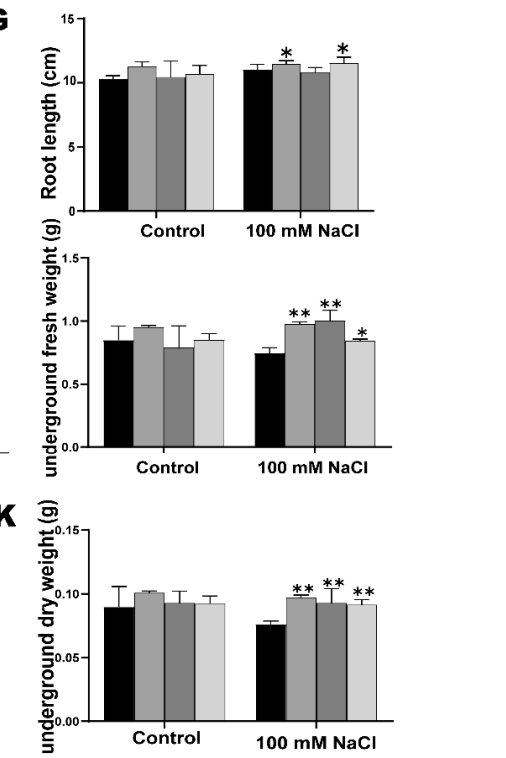

Figure 4. Salt tolerance in greenhouse-raised SiMYB19 transgenic rice plants. (A,B) Phenotypes of WT (Ki) and transgenic rice plants under normal and $100 \mathrm{mM} \mathrm{NaCl}$ conditions. Bar $=2 \mathrm{~cm}$. (C) After $5 \mathrm{~d}$ treatment with $100 \mathrm{mM} \mathrm{NaCl}$, all plants were restored to normal conditions for $7 \mathrm{~d}$. Bar $=2 \mathrm{~cm}$. (D) Survival rates of WT and transgenic rice plants after restoration to normal conditions. (E) Malondialdehyde (MDA) content. (F-K) Plant height, root length, aboveground fresh weight, underground fresh weight, aboveground dry weight, and underground dry weight under normal growth conditions and $100 \mathrm{mM} \mathrm{NaCl}$ treatment. Data are means $\pm \mathrm{SD}(\mathrm{n}=4),{ }^{*} p<0.05,{ }^{* *} p<0.01$, $t$-test.

\subsection{SiMYB19 Overexpression Increased the Yield of Field-Grown Transgenic Rice Subjected to High Salt Stress}

We selected the optimal transgenic line OE- 6 and assessed its salt tolerance in the field. We set up the control (CK; water), $0.3 \%(w / v) \mathrm{NaCl}$, and $0.5 \%(w / v) \mathrm{NaCl}$ treatments. For the control, OE- 6 was taller than the WT (Figure 5A). Under $0.3 \%$ and $0.5 \%(w / v)$ $\mathrm{NaCl}, \mathrm{OE}-6$ was taller and healthier than the WT. Moreover, the differences in health status between OE-6 and WT increased with salt concentration (Figure 5A). Under $0.3 \%(w / v)$ $\mathrm{NaCl}$, the plant height and grain weight per plant were significantly $(p<0.01)$ higher for OE-6 than the WT (Figure 5B,C). Under $0.3 \%(w / v) \mathrm{NaCl}$, the salt tolerance indices of the WT and OE- 6 were $98 \%$ and $60 \%$, respectively, and the difference was significant $(p<0.01)$ (Figure 5D). Both the salt tolerance and relative salt tolerance indices decreased with increasing salt tolerance (Figure 5D). The relative salt tolerance index of OE-6 was significantly lower than that of the WT $(p<0.01)$ (Figure 5E). Thus, OE-6 exhibited a higher salt tolerance than the WT in the field. In the salt ponds containing $0.3 \%(w / v) \mathrm{NaCl}$, OE-6 grew better and had higher salt tolerance than the WT (Figure 5F). 
$\mathbf{A}$
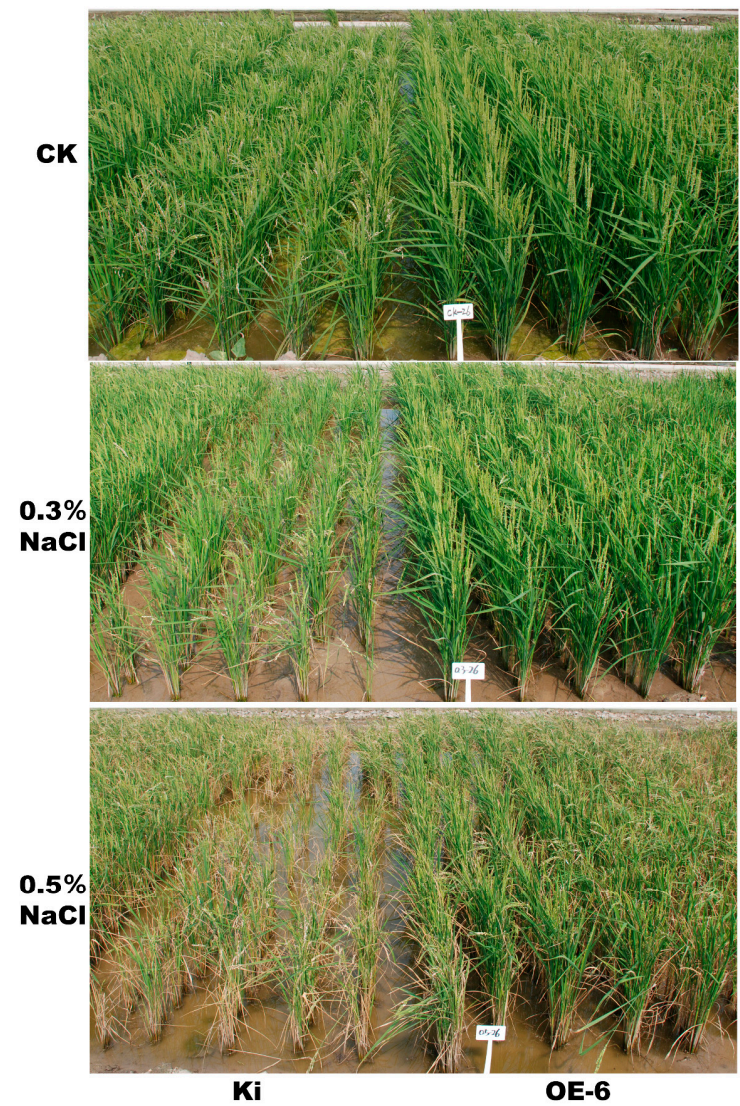

B

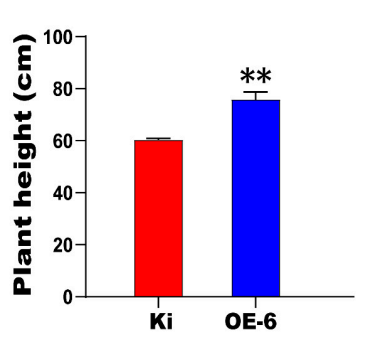

D

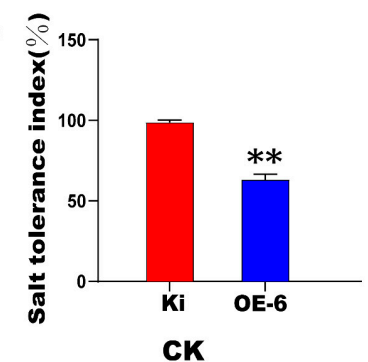

$\mathbf{F}$

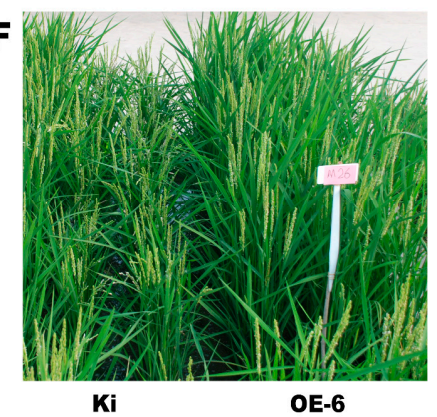

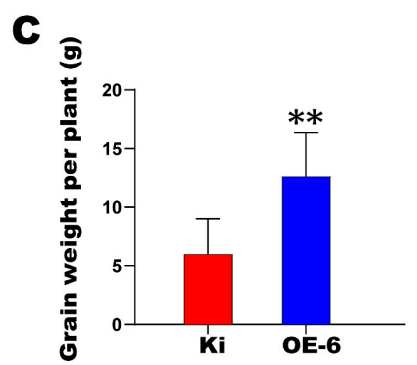

$\mathbf{E}$

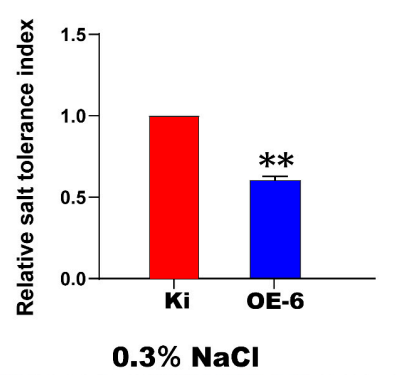

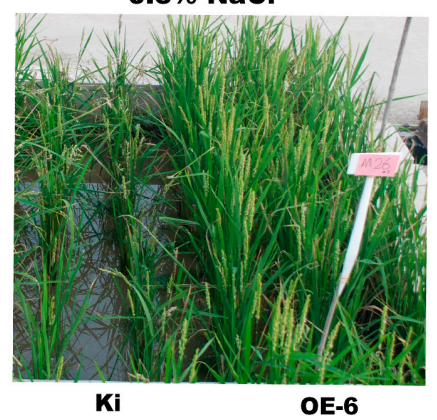

Figure 5. Salt tolerance analysis of SiMYB19 transgenic rice grown in the field and in salt ponds. (A) Phenotypes of transgenic rice line OE-6 and WT (Ki) under normal field conditions (CK), $0.3 \%$ $(w / v) \mathrm{NaCl}$, and $0.5 \%(w / v) \mathrm{NaCl}$. (B,C) Plant height and yield per WT and OE-6 plant under $0.3 \%$ $(w / v) \mathrm{NaCl}$ in the field. (D,E) Salt tolerance and relative salt tolerance indices of WT and OE-6 in the field. (F) Phenotypes of WT and OE-6 under normal conditions and $0.3 \%(w / v) \mathrm{NaCl}$ treatment in salt ponds. ${ }^{* *} p<0.01$.

\subsection{Salt Tolerance, $A B A$, and Drought Stress Response in OE-6}

A salt tolerance analysis showed that the germination rate of OE- 6 was higher than that of the WT under $100 \mathrm{mM}, 200 \mathrm{mM}$, and $250 \mathrm{mM} \mathrm{NaCl}$ (Figure 6A,C-F). After $7 \mathrm{~d}$, the final germination rate of OE-6 was significantly higher than that of the WT (Figure S3). Thus, OE-6 had stronger salt tolerance than the WT during germination. ABA is the main stress-related phytohormone [16]. We analyzed the sensitivity of transgenic rice to ABA treatment using tungstate, an ABA synthesis inhibitor. The germination rate of OE- 6 was lower than that of the WT under normal conditions (Figure 6B,C) and the ABA content of OE-6 was higher than that of the WT (Figure $6 \mathrm{H}$ ). Under $5 \mathrm{mM}$ tungstate, however, the seed germination rates (Figure 6B,G) and the ABA levels (Figure 6H) of both OE-6 and the WT were similar. Therefore, SiMYB19 transgenic rice had relatively greater sensitivity to ABA treatment and SiMYB19 is implicated in ABA signaling.

Based on SiMYB19 upregulation induced by PEG in the early growth stages (Figure 2C), we conducted another soil drought experiment. After $15 \mathrm{~d}$ severe water restriction followed by $5 \mathrm{~d}$ irrigation, OE-6 showed better growth (Figure S4A) and significantly increased survival rate (Figure S4B) compared with the WT. Hence, OE-6 had a certain degree of drought tolerance. 
$\mathbf{A}$

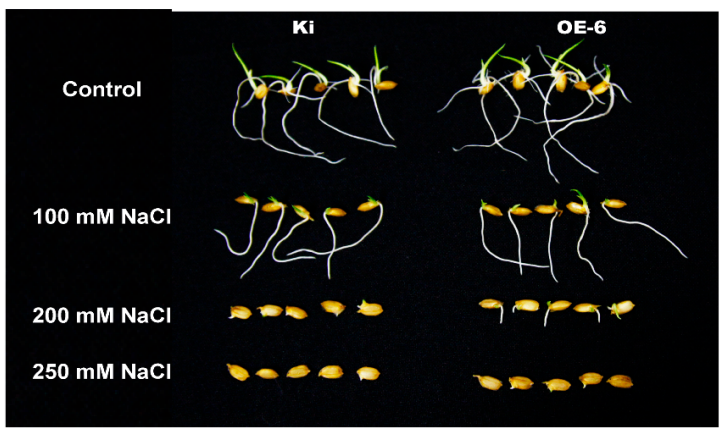

C

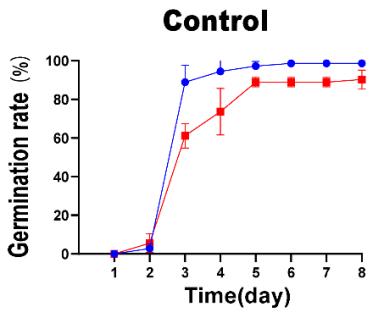

5 mM Tungstate

C

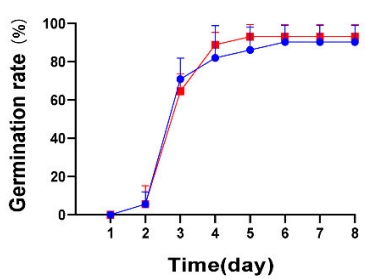

D

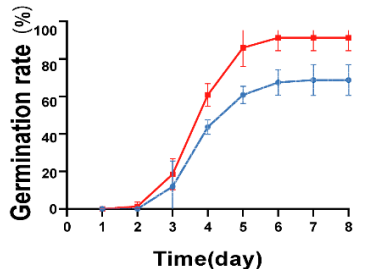

$5 \mu \mathrm{M}$ ABA

\section{$\mathbf{H}$}

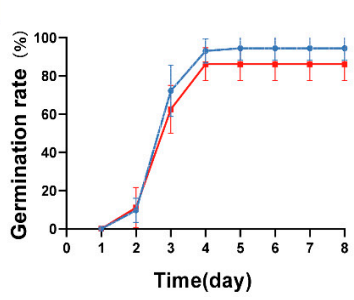

$\mathbf{B}$

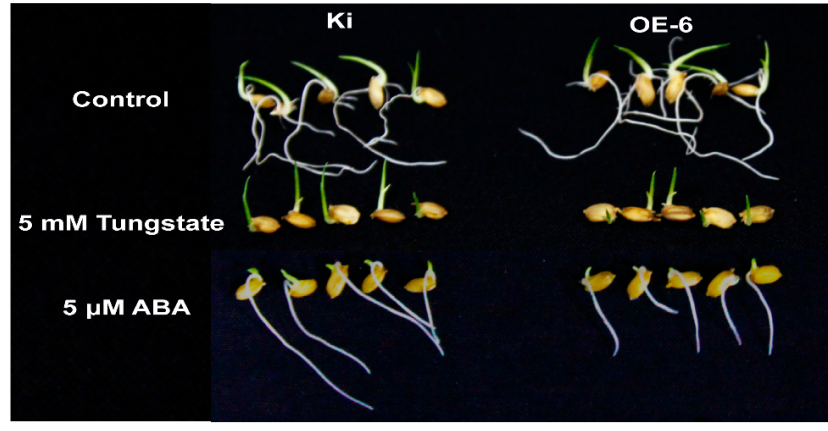

E

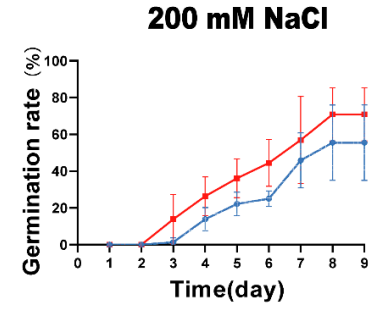

F

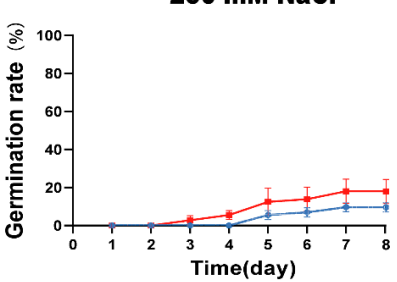

$\rightarrow$ Ki
$\rightarrow$ OE-6

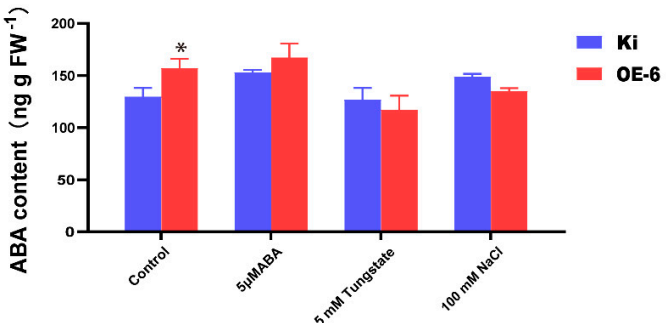

Figure 6. ABA sensitivity analysis of SiMYB19 transgenic rice. (A) Seed germination rates of WT and OE-6 exposed to various $\mathrm{NaCl}$ concentrations ( $n=3 ; 24$ seeds/replicate). (B) Seed germination rates of WT and OE-6 under control and $5 \mathrm{mM}$ tungstate treatments. $(\mathbf{C}-\mathbf{H})$ Seed germination rates of WT and OE- 6 under control, $100 \mathrm{mM} \mathrm{NaCl}, 200 \mathrm{mM} \mathrm{NaCl}, 250 \mathrm{mM} \mathrm{NaCl}$, and $5 \mathrm{mM}$ tungstate treatments. (I) ABA levels in OE-6 and WT. Data are means $\pm \mathrm{SD}(n=3),{ }^{*} p<0.05, t$-test.

\subsection{Expression Analysis of ABA- and Salt Stress-Related Genes in SiMYB19 Transgenic Rice}

We used qRT-PCR to analyze the expression of the gene that synthesizes ABA in SiMYB19 transgenic rice and determine whether salt tolerance is related to ABA pathway gene expression. Under both the control and salt treatments, expression of the ABA synthesis gene OsNCED3 (9-cis-cyclocarotenoid dioxygenase) was higher in the transgenic plants than the WT (Figure 7A). The expression levels of the ABA signal transduction genes OsPK1 (pyruvate kinase 1) and OsABF2 (ABRE-binding factor 2) were higher in OE-6, OE-8, and OE-9 than the WT (Figure 7B,C). LEA (late embryogenesis abundant proteins) improve plant salt tolerance and drought resistance [17]. Here, OsLEA7 expression was higher in the transgenic rice lines than the WT (Figure 7D). 
$\mathbf{A}$
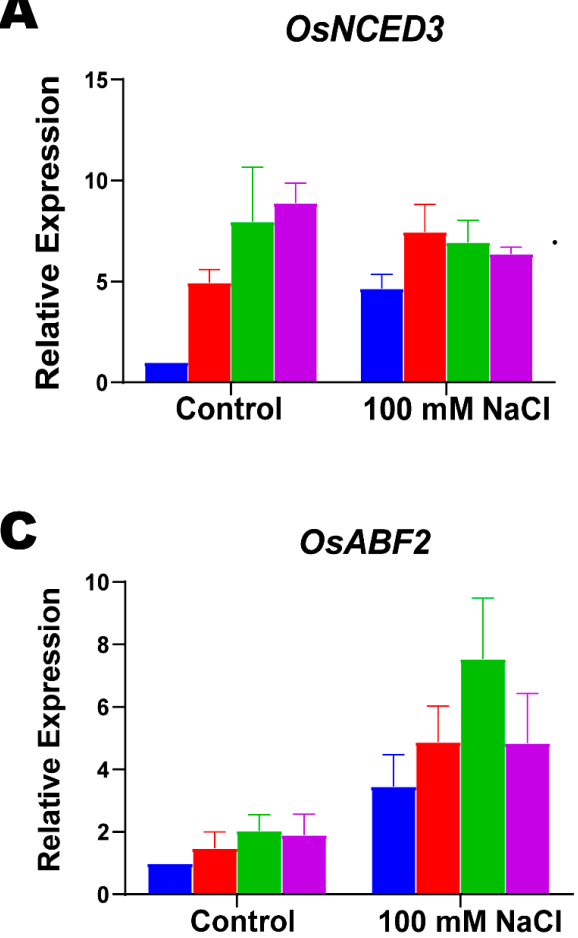

$\mathbf{B}$

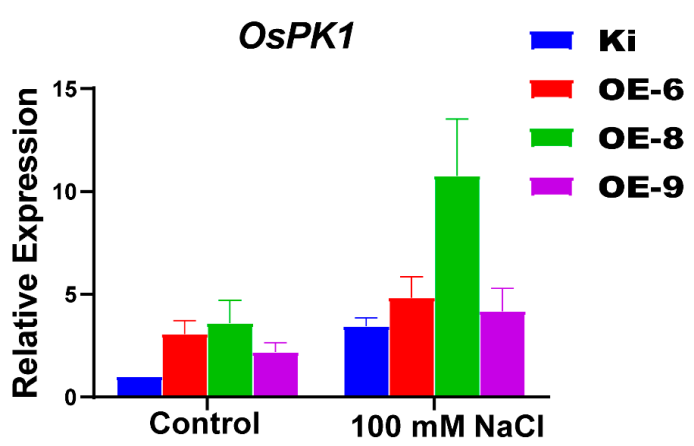

$\mathbf{D}$

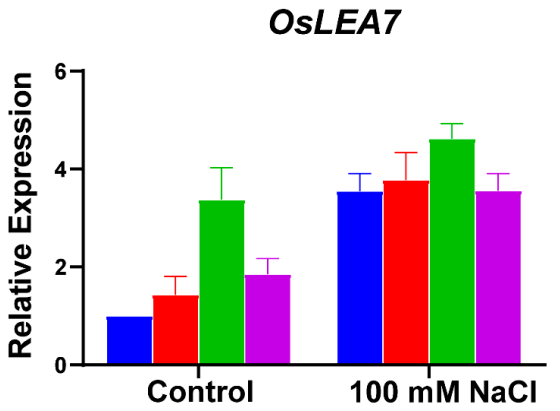

Figure 7. Expression analysis of genes related to ABA synthesis and ABA pathways in SiMYB19 transgenic and WT plants. (A) Relative expression levels of ABA synthesis-related gene OsNCED3 in WT and transgenic rice. (B,C) Relative expression levels of ABA signal transduction pathway-related genes OsPK1 and OsABF2. (D) Relative expression levels of stress-related gene OsLEA7.

\section{Discussion}

\subsection{SiMYB19 Is a Positive Regulator That Modulates Field Crop Salt Stress Tolerance}

The present study demonstrated that SiMYB19 overexpression significantly improves salt tolerance in transgenic rice grown in the greenhouse and field. Salinization seriously affects crop growth, yield, and total agricultural production $[18,19]$. The current global area of salinized land is $~ 954$ million $\mathrm{hm}^{2}$, accounts for $7 \%$ of the total land area worldwide, and is distributed mainly in Africa, western North America, and Eurasia [20]. In China, the area of saline-alkali land is $\sim 36.66$ million $\mathrm{hm}^{2}$ [21], and most of it has neither been developed nor utilized [22]. Moreover, it is constantly expanding, severely reduces crop growth and grain yield, and threatens the environment and food security. Salt stress may impede crop growth at different developmental stages. The plant growth cycle cannot proceed normally when the soil salt concentration is $>200 \mathrm{mM}[23,24]$. Here, we showed that SiMYB19 overexpression increased salt tolerance in field-grown transgenic rice subjected to $0.3 \%$ $(w / v)$ and $0.5 \%(w / v) \mathrm{NaCl}$. Under these conditions, the transgenic rice could grow and develop normally and had significantly superior grain yield and salt tolerance compared to the WT plants (Figure 5A-C). OsMYB91, OsMYB2, and OsMLD (with MYB TF domain) genes were overexpressed in rice $[7,25,26]$. The results showed that MYB TF had a positive regulatory effect on salt stress, and our newly identified transgenic line OE-6 also showed similar salt stress resistance. Therefore, this study may provide germplasm resources for improving crop salt tolerance. SiMYB19 has potential value in practical cereal crop breeding research. This gene can improve salt tolerance and increase yield in saline-alkali soil. The stable application of SiMYB19 may be validated by multi-year field experiments. If these trials are successful, then SiMYB19 could help expand the global range of arable land. 


\subsection{SiMYB19 Confers Salt Stress Tolerance through an Aba-Dependent Pathway}

The four categories of MYB family proteins are MYB-related, R2R3-MYB, 3R-MYB (R1R2R3-MYB), and 4R-MYB [27,28]. Abiotic stress can induce MYB-related genes. Overexpression of the latter in transgenic plants can increase drought and salt stress resistance. Several R2R3-like MYB TFs participate in stress tolerance [7,29]. Here, we found that SiMYB19 belongs to the R2R3-MYB subgroup (Figure 1B). A phylogenetic tree identified genes with the highest homology, namely, ZmLAF1, OsMYB19, TaMYB18, SiMYB18, and AtMYB45 in maize, rice, wheat, foxtail millet, and Arabidopsis, respectively. The foregoing genes belong to the R2R3-MYB TF family (Figure 1C). SoMYB18 is a sugarcane R2R3-MYB TF that improved salt and drought tolerance in tobacco [30]. MYB15 overexpression improved drought and salt resistance in Arabidopsis by enhancing its ABA sensitivity [31]. Therefore, the R2R3-MYB TF SiMYB19 identified herein may also confer abiotic stress resistance in other plants.

MYB-related genes regulate ABA-related pathways and enable plants to contend with various stressors. ABA reduces water loss from cells in response to osmotic stress [32]. The genes regulating abiotic stress response are involved in both ABA-dependent and ABA-independent signaling pathways [33,34]. In the former, the class A protein phosphatase PP2Cs represses SnRK2s [35], and the ABA signaling pathway is closed. Under stress conditions, ABA production is upregulated, and the phytohormone binds the receptor protein PYR/PYL/RCARs [36] to form a receptor complex with PP2Cs. The SnRK2s is released and is automatically phosphorylated and self-activated [37,38]. It then phosphorylates downstream $\mathrm{ABA}$ TFs and regulates the expression of ABA-responsive genes. Here, we found that the expression levels of $A B A$ synthesis signal transduction genes such as NCED3, ABF2, and PK1 were higher in SiMYB19 transgenic plants than in the WT (Figure 7A-D). The high expression levels of these genes observed in OE-8 may be explained by the fact that the plants were sampled at the early stages of salt stress treatment. SiMYB19 confers salt and drought tolerance in field-grown transgenic rice through the ABA pathway. Previous studies reported that AtMYB44 and AtMYB96 control plant drought and ABA responses through the ABA-dependent signaling pathway [39,40]. OsMYB6 overexpression affected neither the growth nor the development of transgenic rice but increased its ABA sensitivity and enhanced its resistance to drought and salt stress [41]. Overexpression of the MYB19-like protein TaMYB19-B from Triticum aestivum improved stress tolerance in transgenic Arabidopsis. TaMYB19-B was induced by both abiotic stress and exogenous ABA treatment [42]. TaMYB19-B overexpression upregulated RD29A, RD22, and MYB2 in transgenic Arabidopsis. RD29A plays a role in an ABA-independent pathway while $R D 22$ and $M Y B 2$ act through an ABA-dependent pathway [43,44]. No detailed functional analysis of TaMYB19-B-mediated stress tolerance has been performed, and its specific association with ABA is unknown. The present study revealed that the action of SiMYB19 in salt stress tolerance is mediated through ABA synthesis and signal transduction. We confirmed that SiMYB19 is regulated through an ABA-dependent pathway. Nevertheless, the specific mechanism by which SiMYB19 regulates the ABA pathway merits further investigation.

\subsection{SiMYB19 Modulates Drought Stress}

Drought and salt stress negatively influence plant growth and crop productivity [45]. The improvement of crop drought tolerance is vital to food security [46,47]. Here, we found that 10\% $(w / v)$ PEG also induced SiMYB19 (Figure 2C). To clarify the regulatory roles of SiMYB19 on other types of abiotic stress, we conducted a drought tolerant analysis on OE-6 transgenic rice. After $15 \mathrm{~d}$ drought stress and $7 \mathrm{~d}$ recovery, the survival rate of OE-6 was higher than that of the WT (Figure S4). Therefore, the roles that SiMYB19 plays in other types of abiotic stress remain to be determined. 


\section{Methods}

\subsection{Plant Materials, Growth Conditions, and Stress Treatments}

For the gene expression profile analysis, foxtail millet (Yugu1) was grown in pots for $3 \mathrm{wks}$ in a greenhouse at $60 \% \mathrm{RH}$ (relative humidity), $14 \mathrm{~h}$ light at $21^{\circ} \mathrm{C}$, and $10 \mathrm{~h}$ darkness at $24^{\circ} \mathrm{C}$. The plants were then transferred to Hoagland's nutrient solution for $3 \mathrm{~d}$ and subjected to control, salt stress $(100 \mathrm{mM} \mathrm{NaCl})$, osmotic stress (10\% (w/v) PEG6000), abscisic acid (100 mM ABA), auxin (100 mM IAA), or low-nitrogen stress (LN; $0.2 \mathrm{mM}$ $\mathrm{NO}_{3}{ }^{-}$) treatment. Leaves were sampled for the gene expression analysis at $0,1,3,6,12,24$, and $48 \mathrm{~h}$. The roots, stems, and leaves of the control plants were collected for organ-specific SiMYB19 expression analysis. All samples were stored at $-80{ }^{\circ} \mathrm{C}$, and there were three replicates per sample.

For the salt tolerance assay, transgenic rice seeds were germinated in water for $3 \mathrm{~d}$, and the seedlings were transferred to a 96-well plate floating on water in a hydroponic box for $1 \mathrm{wk}$. The seedlings were then transferred to nutrient solution for $1 \mathrm{wk}$ (Table S2). For the salt treatment experiment, 2-wk-old seedlings were transferred to nutrient solution + $100 \mathrm{mM} \mathrm{NaCl}$ for $5 \mathrm{~d}$ and allowed to recover in plain nutrient solution for $7 \mathrm{~d}$. On day 5 of the salt treatment, plant height, root length, aboveground fresh weight, underground fresh weight, aboveground dry weight, and underground dry weight were measured. The malondialdehyde (MDA) content was determined with Keming's MDA Detection Kit (micromethod; Suzhou Comin Biotechnology, Jiangsu, China), and the experiment was performed in triplicate. Seedling survival was evaluated on day 7 of the recovery culture [48]. For the soil-based drought tolerance experiments, the WT and OE-6 (transgenic rice line) seedlings were transferred to soil. At the six-leaf stage, watering was stopped for $15 \mathrm{~d}$ and resumed for another $7 \mathrm{~d}$.

\subsection{Sequence Alignment and Phylogenic Tree Construction}

The exon-intron structure of SiMYB19 was plotted by the gene structure display server (GSDS) program (http:/ /gsds.cbi.pku.edu.cn/, accessed on 5 October 2021). The MYB-like TF sequences were downloaded from https: / / blast.ncbi.nlm.nih.gov/Blast.cgi, accessed on 5 October 2021. The SiMYB19 phylogenic tree was constructed by the neighbor-joining (NJ) method via MEGA7 software (https:/ / www.megasoftware.net/dload_win_gui, accessed on 5 October 2021) [49].

\subsection{Rice Transformation and Subcellular Simyb19 Localization in Foxtail Millet}

The SiMYB19 coding region was amplified by PCR. The PCR product was then digested and ligated into the binary vector pCAMBIA1390 driven by a ubiquitin promoter, and the plasmid pCAMBIA1390-SiMYB19 was obtained. The latter was transformed into Oryza sativa cv. Kitaake via Agrobacterium [50]. The SiMYB19-16318hGFP fusion protein expression vector was constructed by inserting full-length SiMYB19 cDNA into the BamHI restriction site of the 16318hGFP vector [51]. The SiMYB19-16318hGFP fusion protein expression vector was transiently transformed via PEG into foxtail millet protoplasts isolated from plants at the two-leaf and one-heart stages. The $16318 \mathrm{hGFP}$ empty vector was the negative control. Green fluorescence was observed under a confocal laser scanning microscope (Zeiss LSM980; Carl Zeiss AG, Oberkochen, Germany) at $\times 40$. The image was captured with ZEN software (Carl Zeiss AG). The PCR primers are listed in Table S1.

\subsection{Transcription Activation Assay in Yeast}

To understand the transcriptional activation of SiMYB19, negative control pGBKT7(BD) [52] and pGBKT7-SiMYB19(BD-SiMYB19) plasmids were transformed into AH109 yeast [53] according to the supplier's (Clontech Laboratories, Mountain View, CA, USA) instructions. The transformed yeast was spread onto the SD/-Trp solid plate and incubated at $28{ }^{\circ} \mathrm{C}$ for $2 \mathrm{~d}$. Single clones on the SD/-Trp solid medium were shaken for $18 \mathrm{~h}$ and the yeast cells were diluted $10^{0}-, 10^{1}-, 10^{2}$, and $10^{3}$-fold. The diluted yeast cells were spread onto SD/-Trp and SD/-Trp/-His/-Ade/X- $\alpha$ - gal plates and incubated at $30{ }^{\circ} \mathrm{C}$ 
for $3 \mathrm{~d}$. The transcriptional activation of SiMYB19 was identified based on plant growth status. The primers used are listed in Table S1.

\subsection{Salt Tolerance Analyses of SiMYB19 Transgenic Rice in the Field and Salt Ponds}

OE-6 was selected for the subsequent salt tolerance analyses in the salt ponds and the field. For the latter, the treatments included the control, $0.3 \%(w / v) \mathrm{NaCl}$, and $0.5 \%$ $(w / v) \mathrm{NaCl}$. The conductivities of the $0.3 \%(w / v)$ and $0.5 \%(w / v) \mathrm{NaCl}$ treatments were $\sim 6 \mathrm{~ms} / \mathrm{cm}$ and $\sim 10 \mathrm{~ms} / \mathrm{cm}$, respectively. Salt concentrations were kept constant throughout the growth period by irrigating the substrates with saline solution. The duration and intervals of saline irrigation were based on the electrical conductivity of the field water. For the salt pond experiment, the treatments included the control and $0.3 \%(w / v) \mathrm{NaCl}$. Salt tolerance was assessed mainly by observing and comparing relative plant growth. For the field experiment, the yields of the OE- 6 and the WT plants exposed to various salt concentrations were measured at maturity. The salt tolerance index was evaluated as follows:

$$
\text { Salt tolerance index }=\left(1 \times \mathrm{N}_{1}+2 \times \mathrm{N}_{2}+3 \times \mathrm{N}_{3}+4 \times \mathrm{N}_{4}+5 \times \mathrm{N}_{5}\right) / 5 \times \mathrm{N}
$$

where $\mathrm{N}$ is the total number of plants and $\mathrm{N}_{1}, \mathrm{~N}_{2}, \mathrm{~N}_{3}, \mathrm{~N}_{4}$, and $\mathrm{N}_{5}$ are the numbers of plants with $>75 \%, 75-50 \%, 50-25 \%,<25 \%$, and $0 \%$ green leaves, respectively. The relative salt tolerance index is based on the ratio of the transgenic line salt tolerance index to the WT salt tolerance index under the same conditions [54].

\subsection{Salt Tolerance Analysis of Germinating Transgenic Rice Seeds}

Transgenic rice seeds were disinfected with $2.5 \%(w / v)$ sodium hypochlorite solution for $30 \mathrm{~min}$ and soaked in $100 \mathrm{mM} \mathrm{NaCl}, 200 \mathrm{mM} \mathrm{NaCl}$, or $250 \mathrm{mM} \mathrm{NaCl}$. Salt tolerance was evaluated by enumerating the seeds that had germinated under the different salt treatments. To evaluate the ABA sensitivity of SiMYB19 transgenic rice, the seeds were treated with tungstate, an ABA synthesis inhibitor [55] and the germination rates were calculated every $24 \mathrm{~h}$ until all seeds were fully germinated. The experiment was performed in triplicate. The sprouts were then stored at $-80^{\circ} \mathrm{C}$ and their $\mathrm{ABA}$ content was measured with a plant $\mathrm{ABA}$ ELISA Kit (JL13378-48T; Jianglai Biological, Beijing, China).

\subsection{RNA Extraction and $q R T-P C R s$}

The WT and SiMYB19 transgenic OE-6, OE-8, and OE-9 seedlings subjected to various stressors were used in a gene expression analysis. Total plant RNA was extracted from the seedlings by the TRIzol method with a Zhuangmeng Total RNA Extraction Kit (Zoman Biotechnology Co., Beijing, China). The cDNA was synthesized with a TransScript OneStep gDNA Kit (TransGene, Beijing, China). RT-PCR was performed with a Real Master Mix SYBR Green Kit (TransGene, Beijing, China) using the cDNA as the template. The primers are listed in Additional Table S1. The qRT-PCR analysis was conducted with a fluorescent quantitative PCR instrument (ABI7500; Applied Biosystems, Foster City, CA, USA). Relative gene expression was calculated by the $2^{-\triangle \triangle C t}$ method [56] and normalized based on the actin genes in foxtail millet (Si001873m.g) and rice (LOC_Os03g50885).

\section{Conclusions}

SiMYB19 overexpression plays important roles in improving salt tolerance in field crops. Salt tolerance was significantly improved in transgenic rice lines during the germination and seedling stages. Moreover, their yield and salt tolerance in the field and salt ponds were increased. SiMYB19 was induced by drought, high salt, low nitrogen, and ABA. Downstream gene expression analysis indicated that SiMYB19 confers salt tolerance to transgenic field rice through the ABA pathway. Hence, this gene could significantly improve salt tolerance and increase yield in crops grown on saline-alkali land, which, in turn, could expand arable land and maintain food security worldwide. 
Supplementary Materials: The following are available online at https:/ /www.mdpi.com/article/10 $.3390 /$ ijms23020756/s1.

Author Contributions: C.X., M.L., and X.S. designed the experiment. C.X., J.Y., S.W., and M.L. performed the experiment. C.X., J.Y., H.S., H.Y., R.Y., Q.J., and W.T. analyzed the data. C.X., D.S., M.C., Y.Z., C.X., C.W., Z.X., and J.C. conceived and designed the experiments. D.S. and Y.M. coordinated the project. All authors have read and agreed to the published version of the manuscript.

Funding: This research was funded by the State Key Laboratory of Sustainable Dryland Agriculture of Shanxi Agricultural University (No. 202002-2), and the Science \& Technology Innovation Foundation of Shanxi Agricultural University (No. 2020BQ30).

Institutional Review Board Statement: Not applicable.

Informed Consent Statement: Not applicable.

Data Availability Statement: The data that support the findings of this study are available from the corresponding author upon reasonable request.

Conflicts of Interest: The authors declare no conflict of interest.

\section{References}

1. Munns, R. Genes and salt tolerance: Bringing them together. New Phytol. 2005, 167, 645-663. [CrossRef]

2. Muthamilarasan, M.; Prasad, M. Advances in Setaria genomics for genetic improvement of cereals and bioenergy grasses. Theor. Appl. Genet. 2015, 128, 1-14. [CrossRef] [PubMed]

3. Du, H.; Feng, B.; Yang, S.; Huang, Y.; Tang, Y. The R2R3-MYB transcription factor gene family in maize. PLoS ONE 2012, 7, e37463. [CrossRef] [PubMed]

4. Abe, H.; Urao, T.; Ito, T.; Seki, M.; Shinozaki, K.; Yamaguchi-Shinozaki, K. Arabidopsis AtMYC2 (bHLH) and AtMYB2 (MYB) function as transcriptional activators in abscisic acid signaling. Plant Cell 2003, 15, 63-78. [CrossRef]

5. Agarwal, M.; Hao, Y.; Kapoor, A.; Dong, C.; Fujii, H.; Zheng, X.; Zhu, J. A R2R3 type MYB transcription factor is involved in the cold regulation of CBF genes and in acquired freezing tolerance. J. Biol. Chem. 2006, 281, 37636-37645. [CrossRef]

6. Woodger, F.; Millar, A.; Murray, F.; Jacobsen, J.; Gubler, F. The Role of GAMYB Transcription Factors in GA-Regulated Gene Expression. J. Plant Growth Regul. 2003, 22, 176-184. [CrossRef]

7. Yang, A.; Dai, X.; Zhang, W.-H. A R2R3-type MYB gene, OsMYB2, is involved in salt, cold, and dehydration tolerance in rice. J. Exp. Bot. 2012, 63, 2541-2556. [CrossRef]

8. Xu, R.; Wang, Y.; Zheng, H.; Lu, W.; Wu, C.; Huang, J.; Yan, K.; Yang, G.; Zheng, C. Salt-induced transcription factor MYB74 is regulated by the RNA-directed DNA methylation pathway in Arabidopsis. J. Exp. Bot. 2015, 66, 5997-6008. [CrossRef]

9. Wu, J.; Jiang, Y.; Liang, Y.; Chen, L.; Chen, W.; Cheng, B. Expression of the maize MYB transcription factor ZmMYB3R enhances drought and salt stress tolerance in transgenic plants. Plant Physiol. Biochem. PPB 2019, 137, 179-188. [CrossRef]

10. Dong, W.; Gao, T.; Wang, Q.; Chen, J.; Lv, J.; Song, Y. Salinity stress induces epigenetic alterations to the promoter of MsMYB4 encoding a salt-induced MYB transcription factor. Plant Physiol. Biochem. PPB 2020, 155, 709-715. [CrossRef]

11. Fang, Q.; Jiang, T.; Xu, L.; Liu, H.; Mao, H.; Wang, X.; Jiao, B.; Duan, Y.; Wang, Q.; Dong, Q. A salt-stress-regulator from the Poplar R2R3 MYB family integrates the regulation of lateral root emergence and ABA signaling to mediate salt stress tolerance in Arabidopsis. Plant Physiol. Biochem. 2017, 114, 100-110. [CrossRef] [PubMed]

12. Geng, D.; Chen, P.; Shen, X.; Zhang, Y.; Li, X.; Jiang, L.; Xie, Y.; Niu, C.; Zhang, J.; Huang, X.; et al. MdMYB88 and MdMYB124 Enhance Drought Tolerance by Modulating Root Vessels and Cell Walls in Apple. Plant Physiol. 2018, 178, 1296-1309. [CrossRef] [PubMed]

13. Xu, W.; Tang, W.; Wang, C.; Ge, L.; Chen, M. SiMYB56 Confers Drought Stress Tolerance in Transgenic Rice by Regulating Lignin Biosynthesis and ABA Signaling Pathway. Front. Plant Sci. 2020, 11, 785. [CrossRef]

14. Ge, L.; Dou, Y.; Li, M.; Qu, P.; He, Z.; Liu, Y.; Xu, Z.; Chen, J.; Chen, M.; Ma, Y. Setaria italicaSiMYB3 in Foxtail Millet (Setaria italica) Confers Tolerance to Low-Nitrogen Stress by Regulating Root Growth in Transgenic Plants. Int. J. Mol. Sci. 2019, $20,5741$. [CrossRef]

15. Chen, Y.; Yang, X.; He, K.; Liu, M.; Li, J.; Gao, Z.; Lin, Z.; Zhang, Y.; Wang, X.; Qiu, X.; et al. The MYB transcription factor superfamily of Arabidopsis: Expression analysis and phylogenetic comparison with the rice MYB family. Plant Mol. Biol. 2006, 60, 107-124. [CrossRef]

16. Finkelstein, R.; Reeves, W.; Ariizumi, T.; Steber, C. Molecular Aspects of Seed Dormancy. Annu. Rev. Plant Biol. 2008, 59, 387-415. [CrossRef] [PubMed]

17. Babu, R.C.; Zhang, J.; Blum, A.; Ho, T.H.D.; Wu, R.; Nguyen, H.T. HVA1, a LEA gene from barley confers dehydration tolerance in transgenic rice (Oryza sativa L.) via cell membrane protection. Plant Sci. 2004, 166, 855-862. [CrossRef]

18. Kaneko, T.; Horie, T.; Nakahara, Y.; Tsuji, N.; Shibasaka, M.; Katsuhara, M. Dynamic regulation of the root hydraulic conductivity of barley plants in response to salinity/osmotic stress. Plant Cell Physiol. 2015, 56, 875-882. [CrossRef] 
19. Mittler, R. Abiotic stress, the field environment and stress combination. Trends Plant Sci. 2006, 11, 15-19. [CrossRef]

20. Ghassemi, F.; Jakeman, A.J.; Nix, H.A. Salinisation of Land and Water Resources: Human Causes, Extent, Management and Case Studies; CAB International: Wallingford, UK, 1995; p. 544.

21. Zhang, J. Salt-Affected Soil Resources in China; Springer: Berlin/Heidelberg, Germany, 2014; pp. 9-13.

22. Wang, W.J.; He, H.S.; Zu, Y.G.; Guan, Y.; Liu, Z.G.; Zhang, Z.H.; Xu, H.N.; Yu, X.Y. Addition of HPMA affects seed germination, plant growth and properties of heavy saline-alkali soil in northeastern China: Comparison with other agents and determination of the mechanism. Plant Soil 2011, 339, 177-191. [CrossRef]

23. Flowers, T.J.; Colmer, T.D. Salinity tolerance in halophytes. New Phytol. 2010, 179, 945-963. [CrossRef] [PubMed]

24. Munns, R.; Gilliham, M. Salinity tolerance of crops-What is the cost? New Phytol. 2015, 208, 668-673. [CrossRef]

25. Zhu, N.; Cheng, S.; Liu, X.; Du, H.; Dai, M.; Zhou, D.X.; Yang, W.; Zhao, Y. The R2R3-type MYB gene OsMYB91 has a function in coordinating plant growth and salt stress tolerance in rice. Plant Sci. Int. J. Exp. Plant Biol. 2015, 236, 146-156. [CrossRef] [PubMed]

26. Lee, H.J.; Abdula, S.E.; Cho, Y.G. Overexpression of OsMLD Encoding MYB-like DNA Binding Domain Increases Tolerance to Salt Stress in Rice (Oryza sativa L.). Korean J. Breed. Sci. 2012, 44, 100-109.

27. Mmadi, M.; Dossa, K.; Wang, L.; Zhou, R.; Wang, Y.; Cisse, N.; Sy, M.; Zhang, X. Functional Characterization of the Versatile MYB Gene Family Uncovered Their Important Roles in Plant Development and Responses to Drought and Waterlogging in Sesame. Genes 2017, 8, 362. [CrossRef] [PubMed]

28. Shan, T.; Rong, W.; Xu, H.; Du, L.; Liu, X.; Zhang, Z. The wheat R2R3-MYB transcription factor TaRIM1 participates in resistance response against the pathogen Rhizoctonia cerealis infection through regulating defense genes. Sci. Rep. 2016, 6, 28777. [CrossRef] [PubMed]

29. Wei, Q.; Luo, Q.; Wang, R.; Zhang, F.; He, Y.; Zhang, Y.; Qiu, D.; Li, K.; Chang, J.; Yang, G.; et al. A Wheat R2R3-type MYB Transcription Factor TaODORANT1 Positively Regulates Drought and Salt Stress Responses in Transgenic Tobacco Plants. Front. Plant Sci. 2017, 8, 1374. [CrossRef]

30. Shingote, P.R.; Kawar, P.G.; Pagariya, M.C.; Kuhikar, R.S.; Thorat, A.S.; Babu, K.H. SoMYB18, a sugarcane MYB transcription factor improves salt and dehydration tolerance in tobacco. Acta Physiol. Plant 2015, 37, 217. [CrossRef]

31. Ding, Z.; Li, S.; An, X.; Xin, L.; Qin, H.; Wang, D. Transgenic expression of MYB15 confers enhanced sensitivity to abscisic acid and improved drought tolerance in Arabidopsis thaliana. J. Genet. Genom. 2009, 36, 17-29. [CrossRef]

32. Lee, S.C.; Luan, S. ABA signal transduction at the crossroad of biotic and abiotic stress responses. Plant Cell Environ. 2012, 35, 53-61. [CrossRef] [PubMed]

33. Xiong, L.; Schumaker, K.S.; Zhu, J.K. Cell Signaling during Cold, Drought, and Salt Stress. Plant Cell 2002, 14, 165-183. [CrossRef]

34. Zhu, J.-K. Salt and drought stress signal transduction in plants. Annu. Rev. Plant Biol. 2002, 53, 247-273. [CrossRef]

35. Gosti, F.; Beaudoin, N.; Serizet, C.; Webb, A.A.; Vartanian, N.; Giraudat, J. ABI1 protein phosphatase 2C is a negative regulator of abscisic acid signaling. Plant Cell 1999, 11, 1897-1909. [CrossRef]

36. Park, S.; Fung, P.; Nishimura, N.; Jensen, D.; Fujii, H.; Zhao, Y.; Lumba, S.; Santiago, J.; Rodrigues, A.; Chow, T.; et al. Abscisic acid inhibits type 2C protein phosphatases via the PYR/PYL family of START proteins. Science 2009, 324, 1068-1071. [CrossRef] [PubMed]

37. Ng, L.; Soon, F.; Zhou, X.; West, G.; Kovach, A.; Suino-Powell, K.; Chalmers, M.; Li, J.; Yong, E.; Zhu, J.; et al. Structural basis for basal activity and autoactivation of abscisic acid (ABA) signaling SnRK2 kinases. Proc. Natl. Acad. Sci. USA 2011, 108, 21259-21264. [CrossRef] [PubMed]

38. Soon, F.; Ng, L.; Zhou, X.; West, G.; Kovach, A.; Tan, M.; Suino-Powell, K.; He, Y.; Xu, Y.; Chalmers, M.; et al. Molecular mimicry regulates ABA signaling by SnRK2 kinases and PP2C phosphatases. Science 2012, 335, 85-88. [CrossRef] [PubMed]

39. Seo, P.J.; Xiang, F.; Qiao, M.; Park, J.Y.; Park, C.M. The MYB96 Transcription Factor Mediates Abscisic Acid Signaling during Drought Stress Response in Arabidopsis. Plant Physiol. 2009, 151, 275-289. [CrossRef] [PubMed]

40. Jung, C.; Seo, J.; Han, S.; Koo, Y.; Kim, C.; Song, S.; Nahm, B.; Choi, Y.; Cheong, J. Overexpression of AtMYB44 enhances stomatal closure to confer abiotic stress tolerance in transgenic Arabidopsis. Plant Physiol. 2008, 146, 623-635. [CrossRef] [PubMed]

41. Tang, Y.; Bao, X.; Zhi, Y.; Wu, Q.; Guo, Y.; Yin, X.; Zeng, L.; Li, J.; Zhang, J.; He, W.; et al. Overexpression of a MYB Family Gene, OsMYB6, Increases Drought and Salinity Stress Tolerance in Transgenic Rice. Front. Plant Sci. 2019, 10, 168. [CrossRef]

42. Zhang, L.; Liu, G.; Zhao, G.; Xia, C.; Jia, J.; Liu, X.; Kong, X. Characterization of a wheat R2R3-MYB transcription factor gene, TaMYB19, involved in enhanced abiotic stresses in Arabidopsis. Plant Cell Physiol. 2014, 10, 1802. [CrossRef]

43. Yamaguchi-Shinozaki, S.K. Gene networks involved in drought stress response and tolerance. J. Exp. Bot. 2007, 58, 221. [CrossRef] [PubMed]

44. Hirayama, T. Research on plant abiotic stress responses in the post-genome era: Past, present and future. Plant J. 2010, 61, 1041-1052. [CrossRef]

45. Nakashima, K.; Tran, L.S.P.; Nguyen, D.V.; Fujita, M.; Yamaguchi-Shinozaki, K. Functional analysis of a NAC-type transcription factor OsNAC6 involved in abiotic and biotic stress-responsive gene expression in rice. Plant J. 2010, 51, 617-630. [CrossRef] [PubMed]

46. Tester, M.; Langridge, P. Breeding Technologies to Increase Crop Production in a Changing World. Science 2010, 327, 818-822. [CrossRef] [PubMed]

47. Zhu, J.K. Abiotic Stress Signaling and Responses in Plants. Cell 2016, 167, 313-324. [CrossRef] 
48. Li, X.; Yu, B.; Wu, Q.; Min, Q.; Zeng, R.; Xie, Z.; Huang, J. OsMADS23 phosphorylated by SAPK9 confers drought and salt tolerance by regulating ABA biosynthesis in rice. PLoS Genet. 2021, 17, e1009699. [CrossRef]

49. Sudhir, K.; Glen, S.; Koichiro, T. MEGA7: Molecular Evolutionary Genetics Analysis Version 7.0 for Bigger Datasets. Mol. Biol. Evol. 2016, 33, 1870.

50. Komari, T. Efficient transformation of rice (Oryza sativa L.) mediated by Agrobacterium and sequence analysis of the boundaries of the T-DNA. Plant J. Cell Mol. Biol. 2010, 6, 271-282.

51. Yoo, S.; Cho, Y.; Sheen, J. Arabidopsis mesophyll protoplasts: A versatile cell system for transient gene expression analysis. Nat. Protoc. 2007, 2, 1565-1572. [CrossRef] [PubMed]

52. Chien, C.; Bartel, P.; Sternglanz, R.; Fields, S. The two-hybrid system: A method to identify and clone genes for proteins that interact with a protein of interest. Proc. Natl. Acad. Sci. USA 1991, 88, 9578-9582. [CrossRef]

53. Fields, S.; Sternglanz, R. The two-hybrid system: An assay for protein-protein interactions. Trends Genet. 1994, 10, 286. [CrossRef]

54. Abbas, M.K.; Ali, A.S.; Hasan, H.H.; Ghal, R.H. Salt Tolerance Study of Six Cultivars of Rice (Oryza sativa L.) During Germination and Early Seedling Growth. J. Agric. Sci. 2012, 5, 1. [CrossRef]

55. Ma, X.J.; Fu, J.D.; Tang, Y.M.; Yu, T.F.; Yin, Z.G.; Chen, J.; Zhou, Y.B.; Chen, M.; Xu, Z.S.; Ma, Y.Z. GmNFYA13 Improves Salt and Drought Tolerance in Transgenic Soybean Plants. Front. Plant Sci. 2020, 11, 587244. [CrossRef] [PubMed]

56. Li, Q.Q.; Skinner, J.; Bennett, J.E. Evaluation of reference genes for real-time quantitative PCR studies in Candida glabrata following azole treatment. BMC Mol. Biol. 2012, 13, 22. [CrossRef] 